\title{
Analisis lokasi rumah sakit gigi dan mulut Universitas Muhammadiyah Semarang di wilayah Kedungmundu terhadap perspektif pelanggan
}

\section{Analysis of dental and mouth Hospital location University of Muhammadiyah Semarang in Kedungmundu: development of customer perspective}

Dwi Windu Kinanti Arti ${ }^{1}$

${ }^{1}$ Bagian Ilmu Kesehatan Gigi dan Mulut, Fakultas Kedokteran Gigi Universitas Muhammadiyah Semarang (windukinanti@gmail.com)

\section{Abstrak}

Latar Belakang: Rumah Sakit Gigi da Mulut (RSGM) Pendidikan berfungsi menyelenggarakan pelayanan kesehatan gigi dan mulut, sekaligus sebagai sarana proses pembelajaran, pendidikan dan penelitian bagi profesi tenaga kesehatan kedokteran gigi, dan terikat melalui kerjasama dengan Fakultas Kedokteran Gigi. Keberadaan RSGM ini menjadi penting seiring dengan meningkatnya kesadaran masyarakat terhadap kesehatan gigi dan mulut. Perawatan gigi dan mulut bukan hanya ditujukan untuk fungsi kesehatan namun juga fungsi estetis, yang kini dikenal dengan sebutan dental aesthetic. Penelitian ini bertujuan untuk menganalisis daya dukung terhadap lokasi Rumah Sakit Gigi dan Mulut di lingkungan Fakultas Kedokteran Gigi daerah Kedungmundu Semarang

Metode: Penelitian ini merupakan penelitian deskriptif dengan jenis kualitatif. Data primer menggunakan wawancara secara open ended dengan dokumentasi, wawancara, FGD dan data sekunder diperoleh dari dokumen penelitian. diantaranya: dokumen penelitian. Analisis data dilakukan secara diskriptif kualitatif

Hasil: Berdasarkan perspektif pelanggan pengguna RSGM terdekat adalah mahasiswa FKG, warga Muhammadiyah di wilayah Semarang serta masyarakat sekitar RSGM, Warga Muhamamdiyah yang tersebar di berbagai lingkungan seperti sekolah dan organisasi masyarakat. Dimana masyarakat disekitarnya sangat membutuhkan layanan tambahan dalam bidang kesehatan gigi dan mulut.

Kesimpulan: Hasil penelitian ini adalah dilihat dari daya dukung perspektif pelanggan dimana pengguna RSGMP terdiri dari dosen, mahasiswa FKG, masyarakat sekitar Semarang, dan warga Muhammadiyah.

Kata Kunci: Perspektif Pelanggan, RSGM, Universitas Muhammadiyah Semarang. 


\section{Abstract}

Background: Dental Hospital School have a function to as a tools to organize a dental services, education for intern dentist, and a place of research facility for the dentist which having a cooperation with the faculty of dentistry. Dental Hospital School it self being important as same as people awareness of the dental health. Nowadays, dentistry is growing up rapidly, the handling system become more up to date which is the facility has to be integrated and complete. Dental care is not for the dental health only but it can reach the esthetic health care or nowadays we can call it Dental aesthetic.

Method: This Research using a qualitative descriptive method. The primer data have been collected by an interview which is gathered directly from the interviewees by open ended with documentary, interview, FGD (Focus Group Discussion) and the secondary data have been collected from the document which have a related with the research (research document). analized with qualitative description.

Result: Base on customer perspective which is the user of Dental Hospital School is the college student, the people of university and the local communities whom need the extra services of dental health care.

Conclusion: From carrying capacity of costumer which is from lecture, student of dentistry faculty, and people around the dental hospital

Keywords: Costumer, RSGM, University Muhammadiyah of Semarang

\section{PENDAHULUAN}

Kompetensi tenaga kesehatan dapat dikembangkan dengan baik apabila calon tenaga kesehatan memiliki lebih banyak kesempatan mengasah keterampilan ataupun keahlian mereka. Calon dokter gigi yang mengikuti proses pendidikan yang bermutu dengan melakukan magang akan menjadi dokter yang lebih berkompeten daripada dokter yang tidak banyak magang pada saat menempuh pendidikan. Perguruan tinggi yang mendidik calon tenaga kesehatan, khususnya mendidik calon dokter gigi sudah seharusnya juga memiliki tempat untuk menjalankan proses pendidikan profesi, yaitu rumah sakit gigi dan mulut pendidikan.

Universitas Muhammadiyah Semarang (UNIMUS) memiliki sumber daya yang dapat dimanfaatkan untuk mendukung terbentuknya rumah sakit pendidikan. Guna meningkatkan

mutu lulusan Fakultas Kedokteran Gigi UNIMUS, wajib membangun RSGMP sesuai dengan Undang-Undang Republik Indonesia Nomor 20 Tahun 2013 Tentang Pendidikan Kedokteran pasal 6 ayat (3) yang mewajibkan setiap penyelenggara pendidikan memiliki rumah sakit pendidikan. Rumah Sakit Pendidikan merupakan standar pendidikan profesi yang mutlak dimiliki dengan kualitas pelayanan, infrastruktur dan manajemen yang baik. Terbitnya buku ini, maka jaminan akan tersedianya wahana pendidikan untuk dokter dan dokter spesialis, serta pelaksanaan penelitian untuk pengembangan ilmu kedokteran akan tercapai (Kemenkes, 2009).

Kesehatan gigi dan mulut merupakan bagian yang tidak bisa dipisahkan dari pelayanan kesehatan lainnya. Fakultas Kedokteran Gigi membutuhkan sarana prasarana pelayanan kesehatan khusus yang komprehensif berupa Rumah Sakit Gigi dan Mulut sebagai sarana pendidikan dan penelitian sekaligus tempat rujukan untuk perawatan gigi dan mulut. Institusi Fakultas Kedokteran Gigi wajib memiliki Rumah Sakit Gigi dan Mulut Pendidikan. Pelayanan di rumah sakit gigi dan mulut dapat berjalan dengan efektif dan efisien dan masyarakat pun terlindungi maka perlu ditetapkan adanya Rumah Sakit Gigi dan Mulut sesuai dengan Peraturan Menteri Kesehatan (Peraturan Menteri Kesehatan RI No.1173/MENKES/PER/X/2004 tentang Rumah Sakit Gigi dan Mulut)

Sesuai dengan misi Universitas Muhammadiyah Semarang (UNIMUS) maka UNIMUS berencana untuk mendirikan Rumah Sakit Gigi Mulut Pendidikan. Rumah sakit ini didirikan dengan maksud untuk pelayanan pendidikan tentang kesehatan gigi dan mulut. Fakultas Kedokteran Gigi UNIMUS diharapkan dapat menghasilkan tenaga dokter gigi yang semakin baik. Rumah Sakit Gigi Mulut Pendidikan rencananya akan didirikan di lahan dengan luas tanah $4200 \mathrm{~m}^{2}$ milik UNIMUS. Lahan ini terletak dipinggir jalan berada dekat dengan pusat kota Semarang dan berada di 
antara perumahan, perguruan tinggi, serta pertokoan.

RSGM Pendidikan berfungsi untuk menyelenggarakan pelayanan kesehatan gigi dan mulut, sekaligus sebagai sarana proses pembelajaran, pendidikan dan penelitian bagi profesi tenaga kesehatan kedokteran gigi, dan terikat melalui kerjasama dengan fakultas kedokteran gigi. Keberadaan RSGM ini menjadi penting seiring dengan meningkatnya kesadaran masyarakat terhadap kesehatan gigi dan mulut. Perkembangan dunia kedokteran gigi dan mulut telah berkembang sedemikian pesatnya. Jenis penanganannya pun semakin beragam, sehingga fasilitas pelayanannya dituntut semakin lengkap dan terpadu. Perawatan gigi dan mulut bukan hanya ditujukan untuk fungsi kesehatan semata namun juga fungsi estetis, atau yang kini tengah marak dengan sebutan dental aesthetic, yaitu suatu penanganan terhadap gigi dan perawatannya sebagai bagian dari kecantikan di samping tetap memperhatikan fungsi-fungsi konvensional kedokteran gigi (Yuanita, 2009: 2).
Pendirian RSGM sejak awal perlu diposisikan dan diukur dalam kerangka merealisasikan tujuan organisasi tersebut. Metode yang tepat digunakan untuk melihat keterkaitan antara RSGM dengan berbagai aktivitas UNIMUS secara keseluruhan adalah dengan menyusun perencanaan menggunakan instrumen balanced score card (BSC). Balanced Scorecard diciptakan untuk mengatasi masalah tentang kelemahan sistem pengukuran kinerja eksekutif yang berfokus hanya pada aspek keuangan. Selanjutnya, BSC mengalami perkembangan pada implementasinya, tidak hanya sebagai alat pengukur kinerja ekesekutif, namun meluas sebagai pendekatan dalam penyusunan rencana strategik. Yuwono, dkk (2003) menguraikan langkah-langkah BSC digunakan dalam keseluruhan proses penyusunan rencana. Tahapan penyusunan rencana pada dasarnya terdiri atas kegiatan perumusan strategi dan perencanaan strategis itu sendiri.

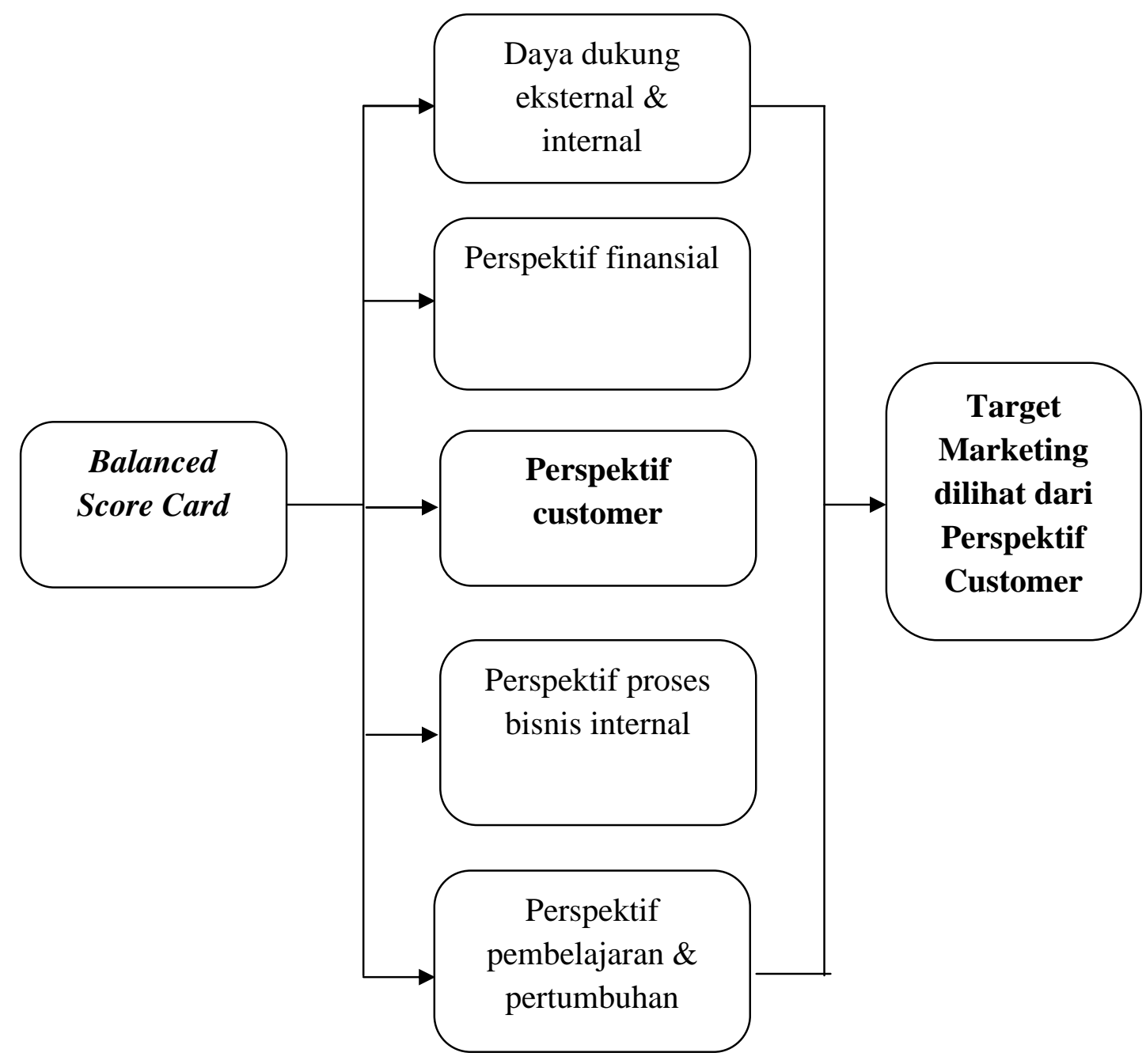


Penelitian ini bertujuan untuk menganalisis daya dukung terhadap lokasi Rumah Sakit Gigi dan Mulut di lingkungan Fakultas Kedokteran Gigi daerah Kedungmundu Semarang dilihat dari: 1) daya dukung perspektif pelanggan. Perspektif pelanggan memungkinkan para manajer unit bisnis untuk mengartikulasikan strategi yang berorientasi dengan pelanggan dan pasar yang akan memberikan

\section{METODE PENELITIAN}

Penelitian ini dilaksanakan dengan jenis penelitian deskriptif menggunakan data kualitatif. Penelitian kualitatif digunakan karena data penelitian harus digali dengan cara wawancara mendalam. Subjek penelitian ini terdiri dari: 1) pengurus yayasan perguruan tinggi Muhammadiyah, pihak rektorat dan dekanat Fakultas Kedokteran Gigi UNIMUS. 2) subjek yang berada pada level operasional yaitu dosendosen Fakultas Kedokteran Gigi yang tergabung dalam tim RSGM, konsultan keuangan, akuntan internal UNIMUS, 3) pengurus yayasan penyelenggara UNIMUS, 4) PDGI dan Dinas Kesehatan Provinsi Semarang. Data dikumpulkan melalui wawancara, focus group discussion (FGD), observasi dan studi dokumen.

Wawancara ditujukan kepada informan yaitu subjek penelitian. Pada pelaksanaan penelitian ini, wawancara mendalam kepada informan yang dimaksud semuanya direkam, lalu dibuat dalam bentuk transkrip. Selanjutnya dilakukan identifikasi atas temuan-temuan yang adasebanyak 7 responden dilakukan wawancara secara terpisah yaitu wawancara kepada ketua BPH, Rektor, Ketua PDGI, dan kepala Dinkes Kota Semarang.. keuntungan finansial masa depan yang lebih besar (Kaplan dan Norton, 2007). Sasaran strategik dari perspektif proses bisnis ini adalah organizational capital seperti meningkatnya kualitas proses layanan kepada customer, proses pelayanan klinis kepada customer, dan penerapan insfrastruktur teknologi yang memudahkan pelayanan kepada customer (Yuwono,dkk, 2003).

Focus Group Discussion dilakukan dengan cara mengundang pihak-pihak yang berkepentingan terhadap rumah sakit untuk mengikuti diskusi kelompok. Fokus diskusi yaitu menggali argumentasi tentang pentingnya Rumah Sakit Gigi dan Mulut Pendidikan (RSGMP). Pengumpulan data melalui Focus Group Discussion (FGD) diikuti oleh tim dosen dan dekan FKG UNIMUS. Analisis data dilakukan secara diskriptif kualitatif dengan langkah-langkah analisis yaitu : 1) Editing, 2) Koding, 3) Penyajian data, dan 4) pembahasan.

\section{HASIL DAN PEMBAHASAN}

Pengguna RSGMP yang terdekat adalah mahasiswa FKG, warga Muhammadiyah di wilayah Semarang serta masyarakat sekitar RSGM. Warga Muhammadiyah tersebar di berbagai lingkungan seperti sekolah-sekolah dan organisasi kemasyarakatan. Masyarakat disekitarnya sangat membutuhkan layanan tambahan dalam bidang kesehatan gigi dan mulut. Daya dukung customer ini didapat dari hasil wawancara seperti tampak dalam coding data pada Tabel 1.

Tabel 1. Koding Data Perspektif Customer

\begin{tabular}{lclll}
\hline & BPH & Rektor & Dekan & Dosen 1 \\
\hline $\begin{array}{l}\text { Masyarakat/ } \\
\text { pasien }\end{array}$ & - & $\begin{array}{l}\text { Masyarakat } \\
\text { datang untuk } \\
\text { memeriksakan } \\
\text { diri }\end{array}$ & $\begin{array}{l}\text { Masyarakat makin } \\
\text { senang karena } \\
\text { tertampung } \\
\text { layanannya }\end{array}$ & $\begin{array}{l}\text { Dari kesehatan, } \\
\text { masyarakat terdekat } \\
\text { lebih merasakan } \\
\text { manfaatnya }\end{array}$ \\
\hline Mahasiswa & - & - & $\begin{array}{l}\text { Mengirimkan anak } \\
\text { untuk belajar di }\end{array}$ & $\begin{array}{l}\text { Mahasiswa S1 FKG } \\
\text { melanjutkan ke } \\
\text { profesi }\end{array}$ \\
\hline $\begin{array}{l}\text { Warga } \\
\text { Muhammadi-yah }\end{array}$ & $\begin{array}{l}\text { Muhammadi- } \\
\text { yah punya } \\
\text { banyak TK }\end{array}$ & - & - & - \\
\hline
\end{tabular}


Konsumen atau pengguna RSGMP yang utama tetap dari masyarakat. Masyarakat sebagai pasien akan datang memeriksakan diri. Mereka yang merasa belum dilayani dengan baik di RSU akan senang dapat dilayani dengan baik di RSGMP. Masyarakat dari sekitar RSGM lebih berpeluang untuk lebih merasakan manfaatnya.

Pengguna dari kalangan mahasiswa yang utama yaitu mahasiswa FKG sendiri terutama untuk mendapatkan pendidikan profesi dokter gigi. Mahasiswa di UNIMUS pada umumnya adalah juga warga Muhammadiyah seperti halnya peserta didik di sekolah-sekolah Muhammadiyah dari tingkat TK hingga perguruan tinggi yang ada di kota Semarang dan sekitarnya.

Pendapat responden dari internal UNIMUS tersebut dikuatkan dengan pendapat dari stakeholders terkait yaitu PDGI dan Dinkes Kota Semarang seperti tampak pada Tabel 2.

Tabel 2. Koding Data Perspektif Customer menurut PDGI dan Dinkes

\begin{tabular}{lrll}
\hline & \multicolumn{1}{c}{ PDGI } & \multicolumn{1}{c}{ DinKes } \\
\hline Masyarakat/ & 1. $\begin{array}{l}\text { Pasti akan meningkatkan } \\
\text { pelayanan kesehatan masyarakat. }\end{array}$ & $\begin{array}{l}\text { 1. } \\
\text { Pasien }\end{array}$ & $\begin{array}{l}\text { Penting. Karena RSGM } \\
\text { ini rujukan }\end{array}$ \\
& 2. $\begin{array}{l}\text { RSGMP di Unisula itu saja, } \\
\text { banyak orang yang tidak tahu }\end{array}$ & 2. $\begin{array}{l}\text { Butuh kesehatan juga } \\
\text { estetika }\end{array}$ \\
& 3. Pindah ke RSGM jika melayani & \\
& $\begin{array}{l}\text { BPJS karena pasien di RS tipe A, } \\
\text { antri banyak bahkan peserta }\end{array}$ & \\
& BPJS antri sampai 500 orang & \\
\hline
\end{tabular}


"Hasil koding data pada Tabel 1 dan 2 memperlihatkan bahwa masyarakat umum sebenarnya juga membutuhkan layanan RSGMP seiring dengan kesadaran terhadap estetika. Hal ini menunjukkan potensi amal usaha RSGMP”.

Konsumen, terutama masyarakat umum sangat membutuhkan pelayanan RSGM. Keberadaan RSGM dapat menjawab lama dan panjangnya antrian pasien gigi dan mulut di RS umum. Pasien gigi dan mulut yang di puskesmas atau di dokter praktik juga membutuhkan RSGM sebagai rujukan. Kebutuhan terhadap layanan RSGM bukan hanya pada saat warga merasa sakit karena masyarakat juga sudah mulai memperhatikan estetika atau keindahan gigi.

Pengguna RSGMP yang terdekat adalah mahasiswa FKG, warga Muhammadiyah di wilayah Semarang serta masyarakat sekitar RSGM. Warga Muhammadiyah tersebar di berbagai lingkungan seperti sekolah-sekolah dan organisasi kemasyarakatan. Masyarakat disekitarnya sangat membutuhkan layanan tambahan dalam bidang kesehatan gigi dan mulut.

Sarana bedah mulut yang ada di RSGMP akan menarik minat pasien untuk memanfaatkan layanan di RSGMP. Adanya persepsi bahwa layanan di RS pendidikan hanya oleh tenaga coass dan bukan oleh dokter profesional memang dapat menjadi hambatan bagi masyarakat untuk memeriksakan kesehatan gigi di RSGMP. Hambatan ini harus diatasi dengan membangun trust antara RSGMP dengan masyarakat. Pilihan pada paradigma sehat dapat menjadi keunggulan yang dapat menepis adanya kemungkinan hambatan tersebut.

Komunikasi, kerjasama dan keterlibatan masyarakat dalam pengembangan RSGMP menjadi sarana untuk membangun trust antara masyarakat dengan RSGMP. Hal ini dapat dilakukan dengan mengadakan kegiatan-kegiatan

1. Tjahjono HK. Budaya Organisasional dan Balanced Scorecard. Unit Penerbit Fakultas Ekonomi(UPFE-UMY); Yogyakarta: 2004.

2. Sujudi A. Rumah sakit gigi dan mulut sebagai rumah sakit pendidikan dan pelayanan. Yogyakarta: 2001

3. Ni Ketut Donna Prisilia Tanjung Sari, Penyusunan Key Performance Indicators Berbasis Balanced Score Card;di Rumah Sakit PKU Muhammadiyah Gombong;2010

4. Peraturan Menteri Kesehatan RI No.1173/MENKES/PER/X/2004 Tentang Rumah Sakit Gigi dan Mulut. sosial dan promotif khususnya kepada internal warga Muhammadiyah di sekolah-sekolah ataupun di masyarakat melalui kegiatan bakti sosial dan pembentukan masyarakat binaan. Keterbukaan dalam menjalin komunikasi dapat mendekatkan RSGMP dengan masyarakat. Kesediaan untuk menerima saran-saran dan menindaklanjuti dengan segera dapat membuktikan bahwa RSGM UNIMUS memang sedang berproses untuk maju dan memberikan pelayanan prima.

Sarana bedah mulut yang ada di RSGMP akan menarik minat pasien untuk memanfaatkan layanan di RSGMP. Adanya persepsi bahwa layanan di RS pendidikan hanya oleh tenaga coass dan bukan oleh dokter profesional memang dapat menjadi hambatan bagi masyarakat untuk memeriksakan kesehatan gigi di RSGMP. Hambatan ini harus diatasi dengan membangun trust antara RSGMP dengan masyarakat. Pilihan pada paradigma sehat dapat menjadi keunggulan yang dapat menepis adanya kemungkinan hambatan tersebut.

\section{SIMPULAN}

Hasil penelitian dan pembahasan tentang AnalisaLokasi RSGM UNIMUS di Wilayah KedungMundu dapat diambil kesimpulan sebagai berikut: Customer atau pengguna RSGMP terdiri dari dosen dan mahasiswa FKG, warga Muhammadiyah di wilayah Semarang serta masyarakat sekitar. RSGM. Secara umum, masyarakat sangat membutuhkan tambahan layanan kesehatan gigi dan mulut dikarenakan RSGM di Semarang juga baru 1. Customer tetap harus mendapatkan edukasi tentang pentingnya perawatan gigi dan mulut sesuai dengan paradigma sehat.

\section{DAFTAR PUSTAKA}

5. Peraturan Menteri Kesehatan RI nomor 340/Menkes/Per/III/2010 Tentang Klasifikasi Rumah Sakit.

6. Yuanita, R. (2009), Landasan Program Perencanaan Dan Perancangan Arsitektur Rumah Sakit Gigi Dan Mulut Unissula Di Semarang, Jurusan Arsitektur Fakultas Teknik Universitas Diponegoro

7. Yuwono, Sony.Petunjuk Praktis Penyusunan Balanced Scorecard. Jakarta;PT. Gramedia Pustaka Utama;2003

8. Kaplan dan Norton.Using Balanced Scorecard as a Strategic Management System. Harvard: Harvard Bussines;2007 
64 Dwi Windu Kinanti Arti

9. Kemenkes RI.Pedoman Klasifikasi dan Standar Rumah Sakit PendidikaN;Direktorat Jenderal

Bina Pelayanan Medik Departemen Kesehatan RI;2000 